\title{
EXPERIMENTAL INVESTIGATION OF PRESSURE AND VOID FRACTION CHANGES FOR TWO-PHASE FLOW THROUGH FLOW-RESTRICTING ORIFICES
}

\author{
NAIEF ALMALKI \& WAEL H. AHMED \\ School of Engineering, University of Guelph, Canada
}

\begin{abstract}
In this work, the change of pressure and void fraction of adiabatic air-water two-phase flow through orifices are experimentally investigated. Horizontal pipes with an internal diameter of $25.4 \mathrm{~mm}$ with multiple orifices with area ratios of $0.062,0.14,0.25$ and 0.54 are considered. Both pressure and void fraction distributions upstream and downstream of the orifice are obtained for intermittent flow patterns and are compared with a straight pipe without the restriction for gas superficial velocity of $0.657 \mathrm{~m} / \mathrm{s}$ and liquid superficial velocity of $0.523 \mathrm{~m} / \mathrm{s}$. The flow redistribution across the orifices is also recorded using a high-speed imaging camera at a frame rate of up to $3 \mathrm{kHz}$. The effect of the area ratio on the local pressure and void fraction upstream and downstream of the restriction is investigated. The results show that the fully developed void fraction upstream of the orifice increased with the increase in the pressure-drop across the orifice. Far from the orifice, the values of the average pressure gradient and the time average void fraction of the piping with orifices approached the fully developed values similar to the case of the straight pipe without restriction. The flow pattern changes across the orifice are found to significantly depend on the area ratio.
\end{abstract}

Keywords: two-phase flow, orifices, pressure drop, void fraction.

\section{INTRODUCTION}

Two-phase flow through flow restricting orifices is present in many applications including power generation, oil and gas industries, and food and chemical industries. These type of piping components are used to control the pressure of the system or the direction of the flow or both. Also, they are used for metering purposes to measure flow rate of the two-phase flow or mass quality [1], [2]. They also can be used to relive excessive pressure as it is the case in rupture disc in nuclear and chemical reactors [3], [4]. Moreover, multiple orifice valves (MOV) are used in the oil and gas wellhead applications to control the pressure and flow of the multiphase flow from the well [5]. Differences in the fluid properties of the two phases when passing through orifices makes the dynamic characteristics of the two-phase flow very complex. Further, piping degradation and failures downstream of orifices could lead to catastrophic failures and series loss [6]. Also, the hydrodynamic behaviour and phases redistribution downstream of the orifice is significant to safely operate and reasonably design such systems.

Research on two-phase flow through restricting orifices has been reported by many researchers. Many of these studies were concerned about predicting the pressure drop across the orifices of different sizes and thickness [9]-[14]. Also, extensive work to determine the effect of the orifice geometry as well as its shape on the two-phase flow was performed [4], [5], [15]-[17]. However, limited research has been carried out to evaluate the effect of orifices on void fraction and flow pattern development. For example, Fossa and Guglielmini [18] focused on the effect of the thin and thick orifices of area ratio of 0.54 and 0.73 on the local pressure drop and void fraction for intermittent flows. They reported that the void fraction increases and reaches a maximum value just downstream of the orifice regardless of its thickness. The slip ratio was also calculated using the void fraction measurements and 
compared to the available slip ratio correlations. They concluded that the measured slip ratio just downstream of the orifice is less than the homogenous model while far from the orifice, the slip ratio is predicted by Chisholm [19] and the Armand and Treschev [20] correlations.

A study by Fossa et al. [21] focused on the effect of orifices of area ratio 0.54 and 0.73 on intermittent two-phase flow. Using the impedance technique, the local time averaged void fraction in 2D upstream and 4D downstream were reported. The results showed that the void fraction reaches maximum value at $1 \mathrm{D}$ downstream the orifice. This void fraction value could be double of the upstream one due to change in slip between phases. The void fraction in the fully developed region downstream of the restriction in general increases compare to the fully developed upstream.

Zeghloul et al. [3] performed experiments on two-phase flow through orifice in a vertical pipe with area ratio of 0.54 and 0.73 . In this study, void fraction measurements were conducted in nine locations using conductance method for bubbly, slug and churn flow patterns observed upstream. The axial distribution of the void fraction was investigated and indicated recovery length of 20,10 and 7 pipe diameters downstream of the orifice for bubbly, slug and churn flow patterns respectively. They also recorded that the frequencies of the bubbles both upstream and downstream of the orifice and found to be similar for bubbly and slug flow.

From the above literatures, it can be concluded that not much work has been performed on the effect of orifice area ratio on the two-phase flow structure for area ratio less than 0.5 . Also, not much work has been reported to show the relation between the pressure and the void fraction distribution in horizontal piping structures with an orifice. Therefore, this paper aims to investigate the effect of area ratio less than 0.5 on adiabatic air-water two-phase flow for horizontal pipe. Measurements of pressure and instantaneous void fraction change upstream and downstream of the orifice were carried out for gas superficial velocity of 0.657 $\mathrm{m} / \mathrm{s}$ and liquid superficial velocity of $0.523 \mathrm{~m} / \mathrm{s}$. Pressure and void fraction were recorded upstream and downstream of orifice with area ratio of $0.62,0.14,0.25$ and 0.56 . For the same liquid and gas superficial velocities, the experiments also were carried out for horizontal straight pipe. High speed imaging camera was also used to show the effect of the orifices on the flow pattern development across the orifice.

\section{EXPERIMENTAL FACILITY}

The experimental facility was constructed to simulate air-water mixture flows in a closed loop at the ambient temperature as shown in Fig. 1. Deionized water was pumped from a 310-L tank by a centrifugal pump that was controlled by a variable frequency drive. The liquid flow rate was measured using an Omega turbine flow meter with reading accuracy of $\pm 1.5 \%$ full scale. The air was supplied from main laboratory supply line and controlled by four rotameters of total range of to $100 \mathrm{~L} / \mathrm{min}$ with accuracy of $\pm 2 \%$ full scale. The air and water were mixed in an annular two-phase mixer at a distance of $3 \mathrm{~m}$ upstream of the orifice. The mixer is made of a concentric aluminium tubing with total length of $80 \mathrm{~mm}$ and 25.4 $\mathrm{mm}$ inner diameter. The internal piece of the mixer is made of perforated tube with a total number of 64 holes distributed equally at eight sets spaced $10 \mathrm{~mm}$. Air is injected radially through these holes while water is introduced axially. The two-phase flow mixture was then transported through a horizontal straight pipe with inner diameter of $25.4 \mathrm{~mm}$ and a total length of $2.4 \mathrm{~m}$ both upstream and downstream of the orifice. The pipe is made of clear polycarbonate in order to allow for flow visualization. 


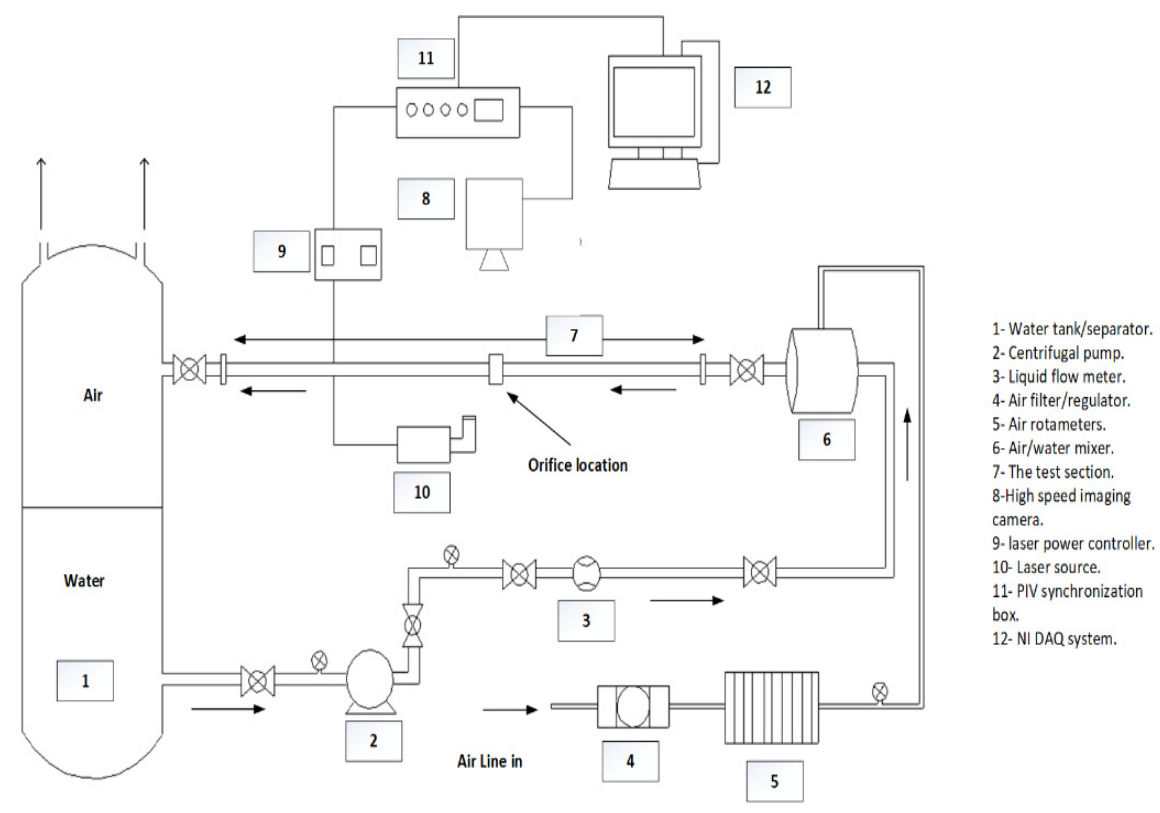

Figure 1: Experimental set-up.

The pressure was measured at nine and thirteen locations upstream and downstream of the orifice using pressure taps made of clear tubing to insure no air was trapped inside which may affect the measurements. These pressure taps were connected to a mechanical pressure scanner from Scannivalve. The output of the pressure signal from the pressure scanner was then divided to two lines and connected to negative ports of two DP15 differential pressure sensors from Validyne with accuracy of $\pm 0.25 \%$ full scale. The two differential pressure sensors have two pressure ranges namely; high pressure range of $350 \mathrm{kPa}$ and low pressure range of $35 \mathrm{kPa}$. The positive ports of the two differential pressure sensors then combined in one line and connected to the first pressure tap after the mixer to represent the reference pressure in the test section. A pressure transducer from Omega (model: PX481A) with accuracy of $\pm 0.3 \%$ full scale and range of $414 \mathrm{kPa}$ was also installed to measure the reference pressure.

The void fraction was measured at total of twelve locations distributed equally upstream and downstream of the orifice. The void fraction was measured using a concave capacitance sensor consists of four electrodes made of copper of $0.12 \mathrm{~mm}$ thickness with $50 \mathrm{~mm}$ length and $24 \mathrm{~mm}$ width. The four electrodes are connected through coaxial cables to a Boonton 7200 DAQ system with sampling frequency up to $3 \mathrm{kHz}$. Detail of the capacitance sensor design adopted in this work was presented by Ahmed [22] and Elsaftawy et al. [23]. Repeatability test for the void fraction measurements indicates that the measured data is within $\pm 5 \%$ full scale. Details on the pressure taps and void fraction sensor measurement locations is shown in Fig. 2.

The flow pattern was visualized using high speed imaging camera from Speedsense with maximum resolution of $1920 \times 1200$ pixels and trigger rate up to 3000 frame per second. 


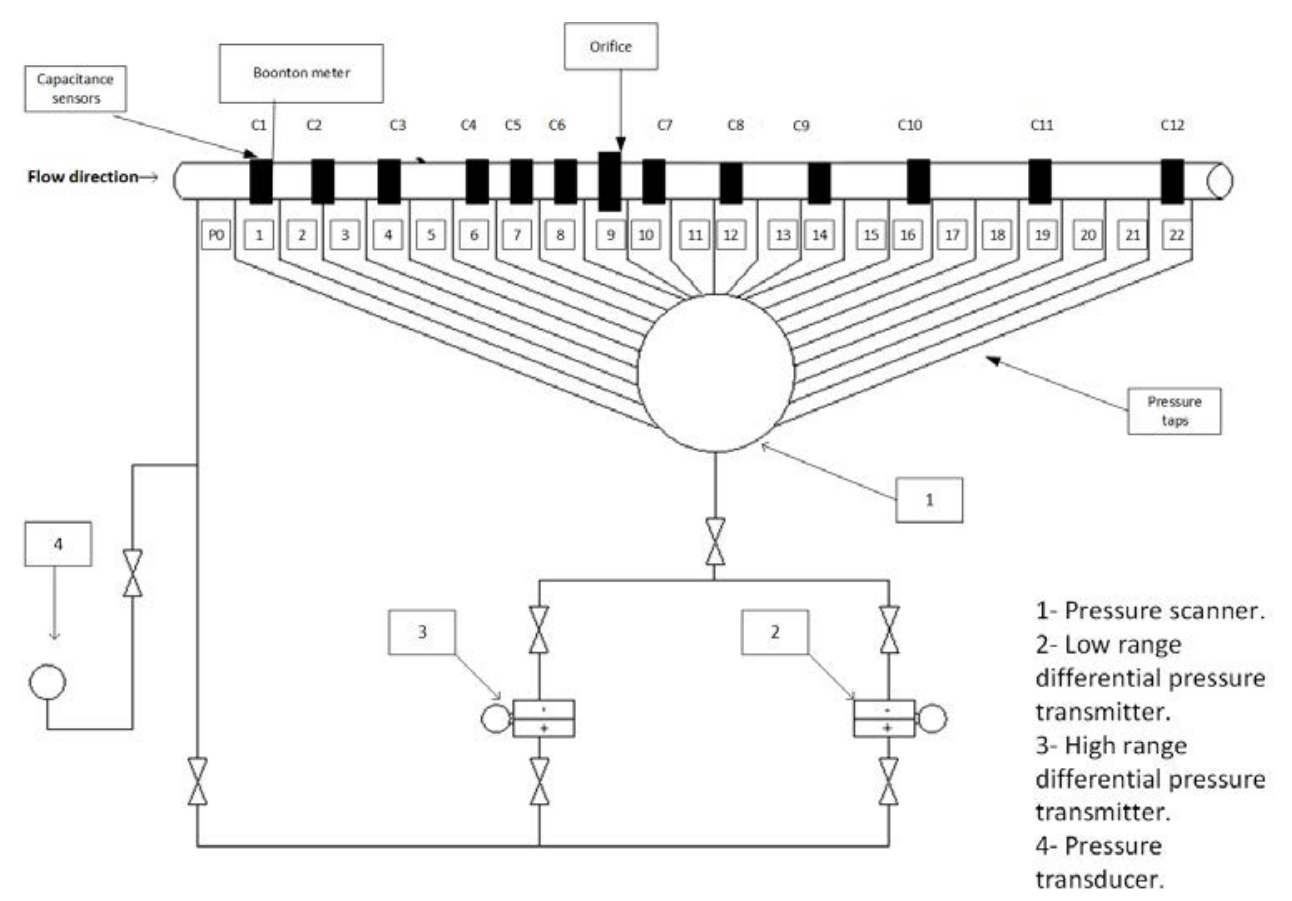

Figure 2: The test section instrumentations.

\section{RESULT AND DISCUSSION}

\subsection{Single-phase pressure drop in orifice}

Single-phase pressure drop across orifices experiments were performed to validate the experimental facility, instrumentation and the experimental procedure. Three thin orifices were used to evaluate the single-phase pressure drop. The total pressure drop caused by the orifice is found by calculating the difference between the upstream best fit equation and the downstream one.

Therefore, the single phase pressure drop caused by an orifice can be calculated as [18]:

$$
\Delta P_{s p}=\frac{2 \rho V^{2}}{2}\left[\left(\frac{1}{\sigma \sigma_{c}}\right)^{2}-1\right],
$$

where $\sigma$ is the area ratio and $\sigma_{c}$ is contraction coefficient. The relationship between the coefficient of discharge and the contraction coefficient is:

$$
\sigma_{c}=\frac{1}{\sigma+\frac{\sqrt{1-\sigma^{2}}}{C_{d}}},
$$

where $C_{d}$ is the coefficient of discharge. It should be noted that the above relations are valid only for thin orifice in which the ratio of the orifice thickness to its diameter (s/d) is less than 0.5 according to Chisholm [19]. On the other hand, the contraction coefficient can be calculated using Chisholm correlation [19] in term of area ratio only as: 


$$
\sigma_{c}=\frac{1}{\left[0.639(1-\sigma)^{0.5}+1\right]}
$$

Summary of the RMSD of the experimental contraction coefficient as well as the ones calculated using Chisholm correlation [19] are presented in Table 1.

Table 1: Summary of the single-phase orifice contraction coefficients.

\begin{tabular}{cccc}
\hline $\begin{array}{c}\text { Area } \\
\text { ratio }\end{array}$ & $\begin{array}{c}\text { Average } \\
\text { contraction } \\
\text { coefficient }\end{array}$ & $\begin{array}{c}\text { RMSD } \\
\text { (Contraction } \\
\text { coefficient vs } \\
\text { Chisholm eqn) }\end{array}$ & $\begin{array}{c}\text { RMSD } \\
\text { (Ideal vs } \\
\text { experimental } \\
\text { pressure drop) }\end{array}$ \\
\hline $\mathbf{0 . 0 6 2}$ & \pm 0.58 & \pm 4.61 & \pm 10.38 \\
\hline $\mathbf{0 . 2 5}$ & \pm 0.62 & \pm 3.33 & \pm 8.33 \\
\hline $\mathbf{0 . 5 4}$ & \pm 0.69 & \pm 1.64 & \pm 5.64 \\
\hline
\end{tabular}

\subsection{The effect of the orifice on the flow structure}

The flow structure upstream and downstream of the orifice was investigated using high speed imaging camera as shown in Fig. 3. It should be mention that the discussion is limited to the presented cases at liquid superficial velocity of $0.523 \mathrm{~m} / \mathrm{s}$ with gas superficial velocity of $0.657 \mathrm{~m} / \mathrm{s}$. In these cases, mainly slug flow upstream of the orifice was observed. The images represent the flow at a distance of 4D upstream and 10D downstream from the orifice. It should be mention here that the flow pattern just downstream of the orifice encounters a considerable fluctuation in the pressure and consequently the density of the gas phase. Therefore, a sequence of flow patterns downstream in the developing region may occur for the same liquid and gas superficial velocities and area ratio used. Three observations can be seen in these images: first; the shape of the gas pocket in the stratified region in the slug flow just upstream of the orifice is affected by the area ratio. It was noticed that the bubbles coalescence and the gas pocket length increase as the area ratio increases. This is mainly due to the decrease in the system pressure. For instance, the pressure upstream in the case of area ratio of 0.62 is about $92 \mathrm{kPa}$ and therefore smaller gas pocket is expected. On the other hand, the upstream pressure in case of area ratio of 0.56 is about $6 \mathrm{kPa}$ which is close to the unrestricted pipe case and consequently a longer gas pocket was observed. Second: once the gas pocket in the slug unit starts to pass the orifice, a separation between the phases occurs. This separation results in a liquid jet surrounded by gas voids as well as thin liquid layers on the pipe wall due to the considerable change in the gas density. When the gas pocket passes completely, the liquid jet with less liquid film on the perimeter of the pipe and gas voids are formed. The length of the liquid jet in the axial direction increases as the area ratio decreases due to momentum increase. Third: the mixture downstream flows in reverse direction of the liquid jet due the lower pressure in the area just downstream of the orifice. Dispersed bubbly flow with high vortices was observed at the location where the liquid jet merges with the back flow. The cycle is repeated as another slug hits the orifice upstream. Also, the fluctuating in the flow pattern in the developing region downstream decreases as the area ratio increases.

\subsection{The effect of the area ratio}

The pressure and averaged void fraction distributions along the test section are shown in Figs 3 and 4 for liquid superficial velocity of 0.523 with gas superficial velocity of $0.657 \mathrm{~m} / \mathrm{s}$. It 
can be seen that the pressure upstream of the orifice increases as the area ratio decreases due to the restriction. Subsequently, the fully developed averaged void fraction upstream $(Z / D=-17.5)$ decreases as the pressure of the system increases due to the compressibility of the gas phase. Far downstream of the orifice, the pressure and the averaged void fraction in the fully developed region $(Z / D=90.5)$ reach values close to the one in the case of the pipe without restriction. This trend was also observed for other cases not reported in this paper. A closer look at the pressure distribution shows that the pressure decreases as the twophase flow approaches the orifice due to the frictional losses. Once the two-phase flow passes through the orifice, the pressure drops dramatically due to the increase in the flow turbulence downstream of the orifice. The magnitude of this pressure drop increases as the area ratio decreases for the same liquid and gas superficial velocities. The pressure then recovers at some distance downstream of the orifice due to the deceleration of the phases.

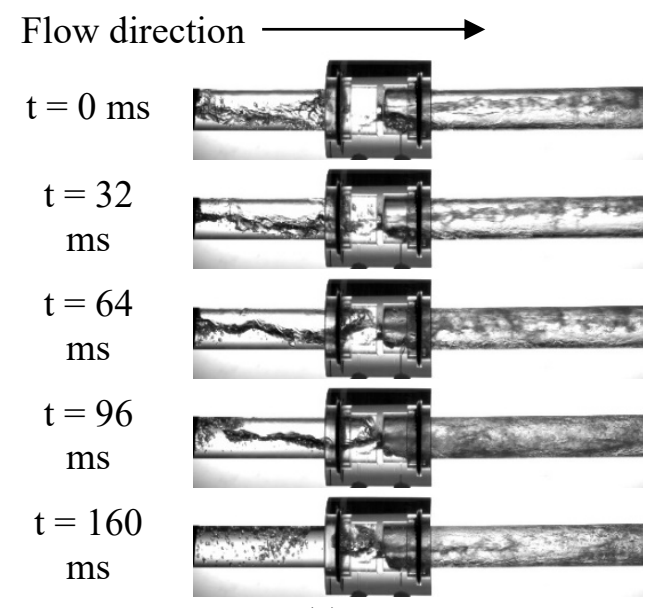

(a)

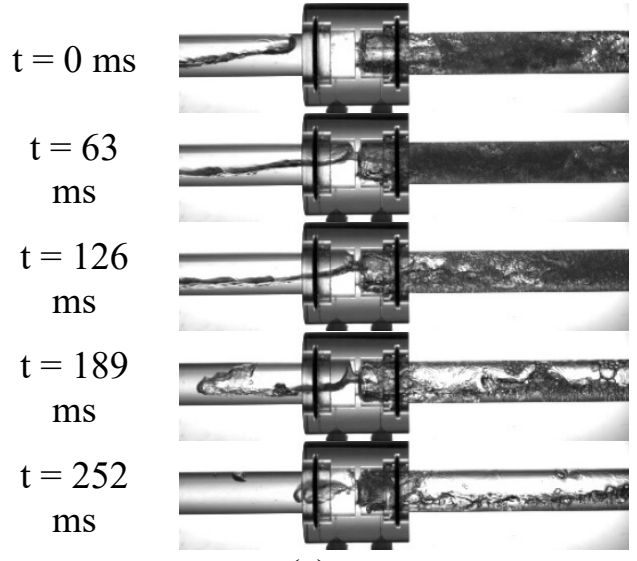

(c)

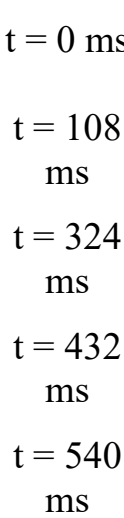

$\mathrm{ms}$

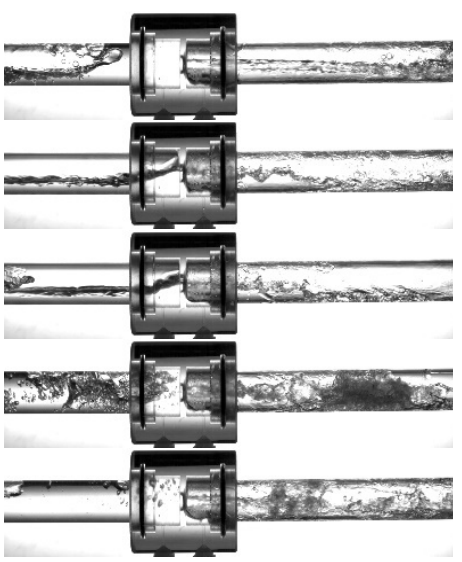

(b)

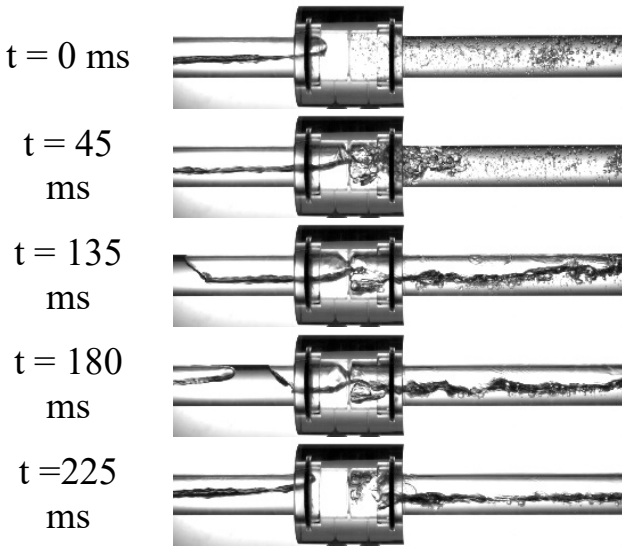

(d)

Figure 3: Time sequence of images showing the phase redistribution downstream of the orifice: (a) $\sigma=0.62$; (b) $\sigma=0.14$; (c) $\sigma=0.25$; (d) $\sigma=0.56$. 


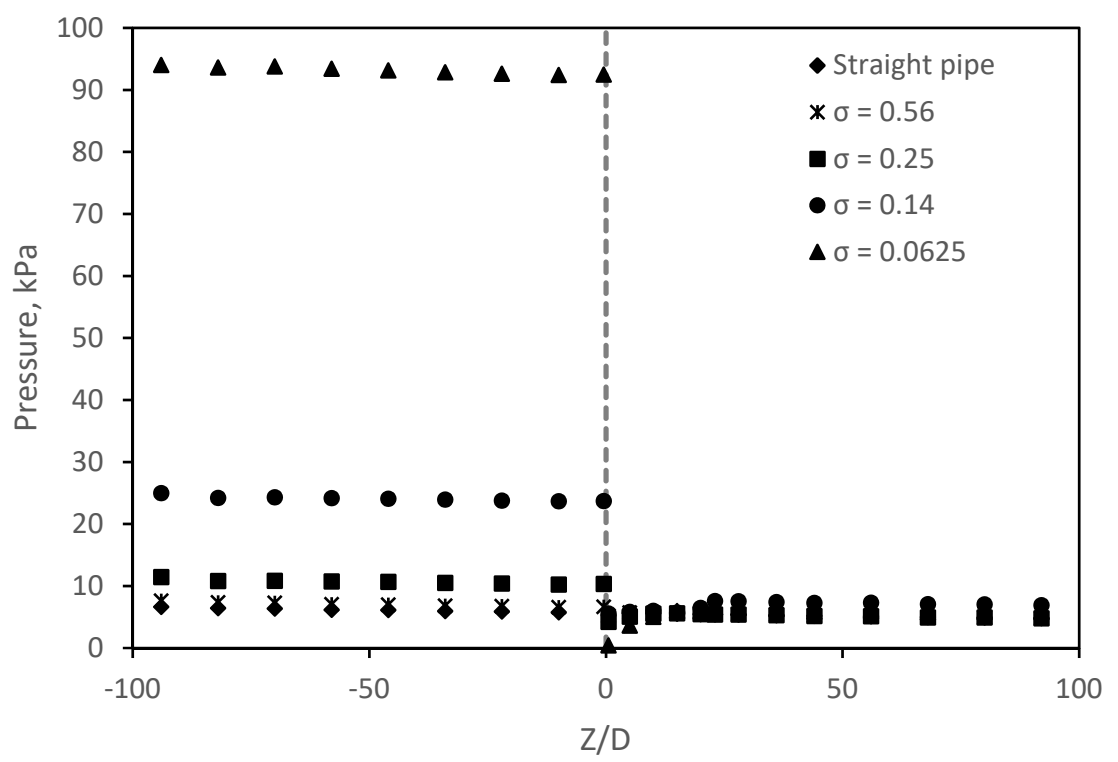

Figure 4: Pressure distribution along the test section.

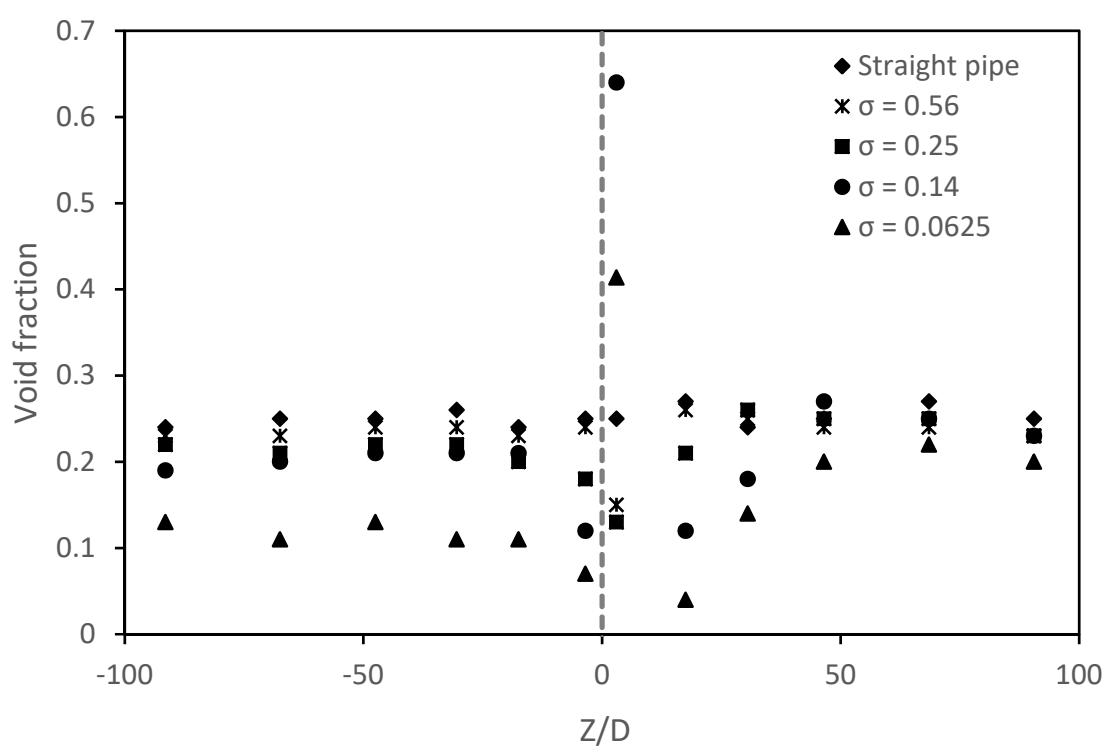

Figure 5: Averaged void fraction along the test section.

This pressure recovery length decreases as the area ratio increases for the same liquid and gas superficial velocities. On the other hand, the averaged void fraction increases as the twophase flow approaches the orifice due the frictional pressure drop. Before the two-phase flow 
passes through the orifice, a slight increase in the pressure and a subsequent decrease in the void fraction just before the orifice $(Z / D=-3.5)$ was noticed due to the presence of the restriction in the flow path. The ratio of the void fraction downstream of the orifice $(Z / D=3)$ to the upstream one $(Z / D=-3.5)$ can be calculated from the presented data as $0.63,0.72,5.33$ and 5.91 for area ratios $0.56,0.25,0.14$ and 0.62 respectively. This clearly indicates that the void fraction just downstream of the orifice increases as the area ratio decreases compare to its initial values upstream. Similar to the pressure downstream, the void fraction downstream starts to recover as the velocities of the phases restore their initial ones upstream. However, the void fraction continues to develop with lesser rate due to bubbles coalescence as well as the frictional pressure drop. Therefore, it is expected that the fully developed void fraction downstream of the orifice to increase compared to the upstream value. This is clear from the void fraction distribution for the case of area ratio of 0.62 in which it increases from 0.11 at $Z / D=-17.5$ upstream to 0.2 at $Z / D=90.5$ downstream.

\subsection{Spatial development of the flow pattern across the orifice}

The development of the flow pattern across the orifice is discussed using the time series of the void fraction for the studied area ratios. An example of the time series of the void fraction for area ratio of 0.62 is shown in Fig. 7. This graph represents the time series of the void fraction at one location upstream $(Z / D=-3.5)$ and six locations downstream $(Z / D=3,17.5,30.5,46.5,68.5$ and 90.5$)$. As expected, the gas pocket of the slug unit upstream increases as the area ratio increases $(Z / D=-3.5)$ as discussed in the previous sections. At the location just downstream of the orifice $(Z / D=3)$, the instantaneous void fraction changes as the two-phase flow passes the orifice for all ratios. The magnitude of this change is more obvious as the area ratio decreases. Also, despite the area ratio used, the flow starts to reform downstream. The distance at which flow pattern changes is however dependant on the area ratio as it decreases as the area ratio increases. Therefore, a fully developed void fraction was observed at $Z / D=17.5,30.5,46.5$ and 68.5 for area ratio of $0.56,0.25,0.14$ and 0.62 respectively. It was also observed that the fully developed void fraction downstream is around 0.4 for all cases. This is because the fact that the pressure downstream of the orifice in the fully developed reign is almost the same for all cases as discussed in the pressure distribution results.

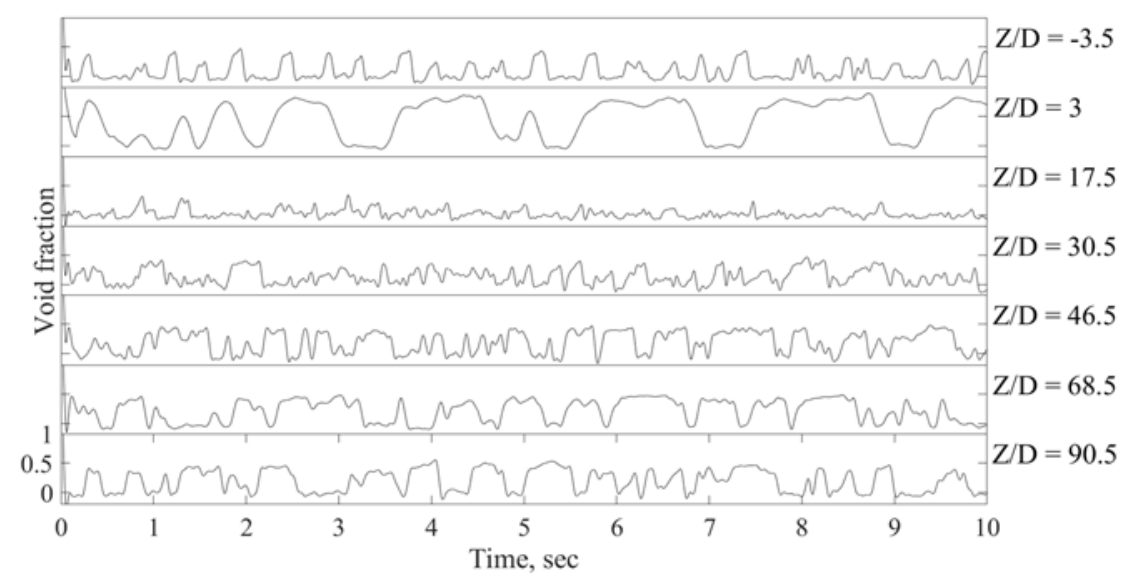

Figure 6: The effect of area ratio on flow pattern development for $\sigma=0.62$. 


\section{CONCLUSION}

A new set of experiments were carried out to study the effect of the area ratio of the orifices on adiabatic air-water two phase flow in horizontal pipe. Four area ratios of $0.62,0.14,0.25$, and 0.56 as well the straight pipe without restriction were used. The two-phase flow was characterized throughout the investigation by pressure and void fraction measurements and high-speed camera. Cases for gas superficial velocity of $0.657 \mathrm{~m} / \mathrm{s}$ and liquid superficial velocity of $0.523 \mathrm{~m} / \mathrm{s}$ were presented. The investigation shows that the fully developed void fraction upstream of the orifice decreases as the area ratio decreases due to the increase in the local pressure upstream. The void fraction just downstream of the orifice increases as the area ratio decreases. For the same liquid and gas superficial velocities, similar pressure and void fraction and subsequently flow pattern were observed in the fully developed region downstream of the orifice regardless of the area ratio used.

\section{ACKNOWLEDGEMENT}

The authors would like to acknowledge the support of Natural Sciences and Engineering Research Council of Canada (NSERC) under the discovery grant program.

\section{REFERENCES}

[1] Lin, Z.H., Two-phase flow measurements with sharp-edged orifices. International Journal of Multiphase Flow, 8(6), pp. 683-693, 1982.

[2] Oliveira, J.L.G., Passos, J.C., Verschaeren, R. \& Geld, C., Mass flow rate measurements in gas-liquid flows by means of a venturi orifice plate coupled to a void fraction sensor. Experimental Thermal and Fluid Science, 33(2), pp. 253-260, 2009.

[3] Zeghloul, A., Azzi, A., Saidj, F., Azzopardi, B.J. \& Hewakandamby, B., Interrogating the effect of an orifice on the upward two-phase gas-liquid flow behaviour. International Journal of Multiphase Flow, 74, pp. 96-105, 2015.

[4] Shannak, B., Friedel, L., Alhusein, M. \& Azzi, A., Experimental investigation of contraction in single- and two-phase flow through sharp-edged short orifice. Forschung im Ingenieurwesen, 11(64), pp. 291-295, 1999.

[5] Alimonti, C., Falcone, G. \& Bello, O., Two-phase flow characteristics in multiple orifice valves. Experimental Thermal and Fluid Science, 34(8), pp. 1324-1333, 2010.

[6] Ahmed, W.H., Bello, M.M., El Nakla, M. \& Al Sarkhi, A., Flow and mass transfer downstream of an orifice under flow accelerated corrosion conditions. Nuclear Engineering and Design, 252, pp. 52-67, 2012.

[7] Ahmed, W.H., Bello, M.M., El Nakla, M., Al Sarkhi, A. \& Badr, H., Experimental investigation of flow accelerated corrosion under two-phase flow conditions. Nuclear Engineering and Design, 267, pp. 34-43, 2014.

[8] Bamidele, O.E., Ahmed, W.H. \& Hassan, M., Two-phase flow induced vibration of piping structure with flow restricting orifices. International Journal of Multiphase Flow, 113, pp. 59-70, 2019.

[9] Sharp, R.M., Two-phase pressure losses in valves and fittings. Master's thesis, Georgia Institute of Technology, 1953.

[10] Chisholm, D., Pressure losses in bends and tees during steam-water flow. NEL Report No. 318, 1967.

[11] Chisholm, D. \& Sutherland, L.A., Prediction of pressure gradients in pipeline systems during two-phase flow. SAGE Journals, 184(3), pp. 24-32, 1969.

[12] Sookprasong, P., Brill, J.P. \& Schmidt, Z., Two-phase flow in piping components. Journal of Energy Resources Technology, 108(3), pp. 197-201, 1986. 
[13] Saadawi, A.A., Grattan, E. \& Dempster, W.M., Two phase pressure loss in orifice plates and gate valves in large diameter pipes. Proceedings of the 2nd Symposium on Two-Phase Flow Modelling and Experimentation, Pisa, Italy, 1999.

[14] Morris, S.D., Two phase pressure drop across valves and orifice plates. Technical Report, European Two Phase Flow Group Meeting, 1985.

[15] Salcudean, M., Groeneveld, D.C. \& Leung, L., Effect of flow-obstruction geometry on pressure drops in horizontal air-water flow. International Journal of Multiphase Flow, 9(1), pp. 73-85, 1983.

[16] Salcudean, M.E. \& Leung, L.K.H., Two-phase pressure drop through obstructions. Nuclear Engineering and Design, 105(3), pp. 349-361, 1988.

[17] Klausner, J. \& Warren, B.A., Developing lengths in horizontal two-phase flow. Journal of Fluids Engineering, 117(3), pp. 512-518, 1995.

[18] Fossa, M. \& Guglielmini, G., Pressure drop and void fraction profiles during horizontal flow through thin and thick orifices. Experimental Thermal and Fluid Science, 26(5), pp. 513-523, 2002.

[19] Chisholm, D., Two-Phase Flow in Pipelines and Heat Exchangers, Longman Group Ed: London, 1983.

[20] Armand, A.A. \& Treschev, G., Investigation of the resistance during movement of the steam-water mixtures in heated boiler pipe at high pressure. Izvestia User. Teplo. Inst. AERE Lib/Trans 816, 4, pp. 1-5, 1947.

[21] Fossa, M., Guglielmini, G. \& Marchitto, A., Two-phase flow structure close to orifice contractions during horizontal intermittent flows. International Communications in Heat and Mass Transfer, 33(6), pp. 698-708, 2006.

[22] Ahmed, W., Capacitance sensors for void-fraction measurements and flow-pattern identification in air-oil two-phase flow. IEEE Sensors Journal, 6(5), pp. 1153-1163, 2006.

[23] Elsaftawy, A., Potts, J. \& Ahmed, W., Oscillation frequency LC-based sensor for characterizing two-phase flows in energy systems. IEEE Sensors, 19(1), 2019.

[24] Roul, M.K. \& Dash, S.K., Single-phase and two-phase flow through thin and thick orifices in horizontal pipes. Journal of Fluids Engineering, 134(9), p. 14, 2012. 